Article

\title{
Effect of Calcination Atmosphere and Temperature on the Hydrogenolysis Activity and Selectivity of Copper-Zinc Catalysts
}

\author{
Oleg Kikhtyanin ${ }^{1}$, Violetta Pospelova ${ }^{2}$, Jaroslav Aubrecht ${ }^{2}$, Miloslav Lhotka ${ }^{3}$ \\ and David Kubička 1,2,*(D) \\ 1 Technopark Kralupy, VŠCHT Praha, Žižkova 7, 27801 Kralupy nad Vltavou, Czech Republic; \\ oleg.kikhtyanin@vscht.cz \\ 2 Department of Petroleum Technology and Alternative Fuels, VŠCHT Praha, Technická 5, \\ 16628 Praha 6-Dejvice, Czech Republic; violetta.pospelova@vscht.cz (V.P.); \\ jaroslav.aubrecht@vscht.cz (J.A.) \\ 3 Department of Inorganic Technology, University of Chemistry and Technology Prague, Technická 5, \\ 16628 Praha 6-Dejvice, Czech Republic; miloslav.lhotka@vscht.cz \\ * Correspondence: david.kubicka@vscht.cz; Tel.:+420-220-446-106
}

Received: 23 September 2018; Accepted: 7 October 2018; Published: 11 October 2018

\begin{abstract}
A series of $\mathrm{CuZn}$ catalysts with a $\mathrm{Cu} / \mathrm{Zn}$ ratio of 1.6 was prepared by the calcination of a single precursor, CuZn-P consisting of an equimolar mixture of aurichalcite and zincian malachite, in three different calcination atmospheres (air, nitrogen, and hydrogen) at three temperatures (220, 350 , and $500{ }^{\circ} \mathrm{C}$ ). All catalysts were characterized by XRD and $\mathrm{N}_{2}$-physisorption to assess their phase composition, crystallite sizes and textural properties and tested in dimethyl adipate (DMA) hydrogenolysis in a batch reactor at $220^{\circ} \mathrm{C}$ and $10 \mathrm{MPa} \mathrm{H}_{2}$. The XRD examination of these catalysts proved that both parameters, calcination temperature and atmosphere, affected the resulting phase composition of the catalysts as well as their crystallite sizes. In an oxidizing atmosphere, $\mathrm{CuO}$ and $\mathrm{ZnO}$ in intimate contact prevailed whereas in inert or reducing atmosphere both oxides were accompanied by $\mathrm{Cu}_{2} \mathrm{O}$ and $\mathrm{Cu}$. The crystallite size of $\mathrm{Cu}_{2} \mathrm{O}$ and $\mathrm{Cu}$ was larger than the size of $\mathrm{CuO}$ and $\mathrm{ZnO}$ thus indicating a less intimate contact between the $\mathrm{Cu}$-phases and $\mathrm{ZnO}$ in catalysts calcined in nitrogen and hydrogen. Catalysts prepared by calcination at $220^{\circ} \mathrm{C}$ and $\mathrm{CuZn}$ catalyst calcined in the air at $350{ }^{\circ} \mathrm{C}$ significantly outperformed the other catalysts in DMA hydrogenolysis with a 59-78\% conversion due to the small crystallite size and intimate contact between the $\mathrm{CuO}$ and $\mathrm{ZnO}$ phases prior to catalyst reduction. Despite the low DMA conversion $(<30 \%)$, transesterification products were the main reaction products with overall selectivities of $>80 \%$ over the catalysts calcined in nitrogen or hydrogen at least at $350{ }^{\circ} \mathrm{C}$. The obvious change in the preferred reaction pathway because of the atmosphere calcination and temperature shows that there are different active sites responsible for hydrogenolysis and transesterification and that their relative distribution has changed.
\end{abstract}

Keywords: hydrogenolysis; transesterification; CuZn catalysts; calcination atmosphere; calcination temperature

\section{Introduction}

Over the past few decades, increasing attention has been paid to green chemistry principles to achieve a higher sustainability of chemical technologies. One of these principles is based on the application of highly efficient catalysts in industrial processes. However, their efficiency alone does not guarantee the overall technological sustainability as some catalyst productions use or produce harmful materials. This is the case of the traditional, highly efficient Adkins catalysts containing chromium that 
have been used for the industrial hydrogenolysis of esters to alcohols since the 1950s [1-3]. Recently, copper-zinc catalysts have been shown to possess significant catalytic activity in the hydrogenolysis of biomass-derived esters [4-6] and could thus replace copper-chromium catalysts that do not meet the highest environmental standards.

Copper-zinc catalysts belong among widely studied catalysts due to a significant interest in the methanol synthesis from synthesis gas [7-9], as well as by the hydrogenation of carbon dioxide [10,11]. From a structural point of view, several studies have concluded that zinc oxide supports the adsorption of hydrogen on the copper surface and ensures the stabilization of the copper dispersion [7,12]. $\mathrm{ZnO}$ has also been suggested to act as a spacer between copper particles supporting high copper dispersion and thus maximizing the specific surface of copper $[7,8,13]$. This is of importance as $\mathrm{Cu}$ is the active component responsible for the hydrogenation and hydrogenolysis activity of catalysts. Nonetheless, the exact nature of the $\mathrm{Cu}$ active sites is still a matter of discussion even in the case of the most studied methanol synthesis [8] and it is not yet sufficiently described in hydrogenolysis catalysts. Recently, the formation of transesterification products during the hydrogenolysis of dimethyl adipate over a $\mathrm{CuZnAl}$ catalyst has been reported [6] and a reaction scheme has been proposed (Scheme 1). However, a clear understanding of the transesterification activity is still lacking. Moreover, due to the sensitivity of the copper-based catalysts to thermal treatment at elevated temperatures, the optimization and stabilization of the distribution of $\mathrm{Cu}$ active sites is challenging and studies dealing with the effect of calcination conditions are rather scarce [14].

Therefore, the present work is focused on a systematic study of the effect of three different calcination gas atmospheres, i.e., air, nitrogen, and hydrogen, on the structure and catalytic performance of catalysts obtained by the calcination of a precipitated $\mathrm{CuZn}$ catalyst precursor at three different temperatures $\left(220,350\right.$, and $\left.500{ }^{\circ} \mathrm{C}\right)$ in these three calcination atmospheres. Particular attention is paid to the effect of the calcination on the relative activity of these CuZn catalysts in the hydrogenolysis and transesterification reactions in order to contribute to a better understanding of both catalytic functions.

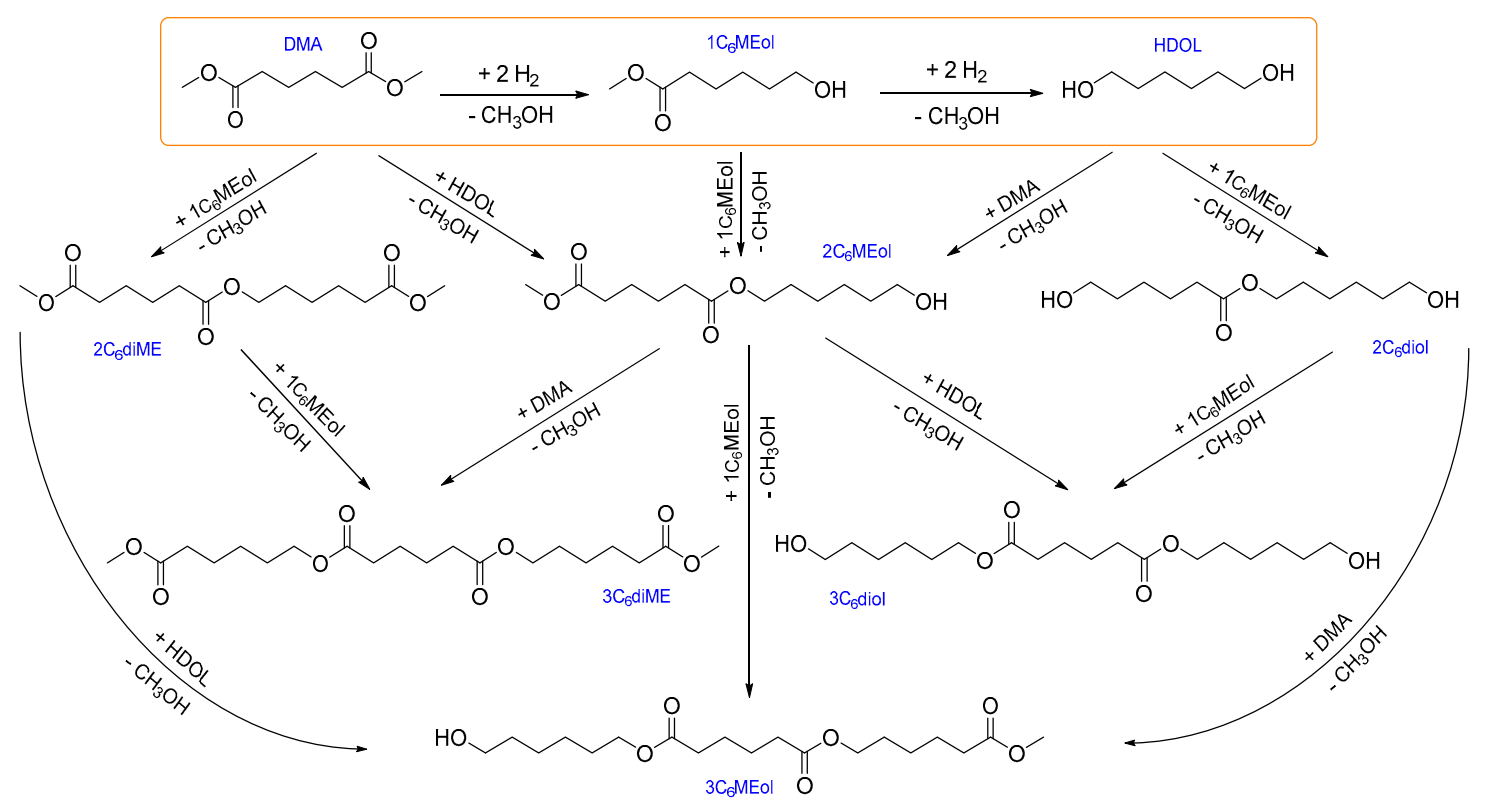

Scheme 1. The proposed reaction network explaining the formation of the transesterification by-products during the hydrogenolysis of dimethyl adipate [6]. DMA is dimethyl adipate, $1 \mathrm{C}_{6} \mathrm{MEol}$ is methyl 6-hydroxyhexanoate, HDOL is hexane-1,6-diol, $2 \mathrm{C}_{6}$ diME is 6-methoxy-6-oxohexyl methyl adipate, $2 \mathrm{C}_{6} \mathrm{MEol}$ is 6-hydroxyhexyl methyl adipate, $2 \mathrm{C}_{6}$ diol is 6-hydroxyhexyl 6-hydroxyhexanoate, $3 \mathrm{C}_{6}$ diME is bis(6-methoxy-6-oxohexyl) adipate, $3 \mathrm{C}_{6} \mathrm{MEol}$ is 6-hydroxyhexyl (6-methoxy-6-oxohexyl) adipate, and $3 \mathrm{C}_{6}$ diol is bis(6-hydroxyhexyl) adipate. 


\section{Results and Discussion}

\subsection{Catalyst Characterization}

The $\mathrm{Cu} / \mathrm{Zn}$ atomic ratio in the synthesized catalyst precursor determined by XRF was 1.6, i.e., very close to that expected from the chemical composition of the solution of copper and zinc nitrates used in the precipitation (1.5). Moreover, it was assumed that all catalyst samples prepared by different thermal treatments had the same chemical composition.

The phase composition of the catalyst precursor, as well as that of the final catalysts, was investigated by XRD. The XRD pattern of the as-prepared CuZn precursor (Figure 1) revealed that this sample was a mixture of two phases, zincian malachite $\left(\left(\mathrm{Cu}_{0.8} \mathrm{Zn}_{0.2}\right)_{2}(\mathrm{OH})_{2} \mathrm{CO}_{3}\right.$; Ref. Code No. 01-079-7851) and aurichalcite $\left(\mathrm{Cu}_{2} \mathrm{Zn}_{3}\left(\mathrm{CO}_{3}\right)_{2}(\mathrm{OH})_{6}\right.$; Ref. Code No. 04-010-3227), found in almost equal amounts.

The XRD patterns of the catalysts prepared by calcination in static air at the three calcination temperatures $\left(220,350\right.$, and $\left.500{ }^{\circ} \mathrm{C}\right)$ are compared with the XRD pattern of the catalyst precursor in Figure 1 . When the catalyst precursor was treated at $220^{\circ} \mathrm{C}$, the phase composition did not change, although the intensity of the XRD reflexes decreased slightly. This can be attributed to the good thermal stability of zincian malachite and aurichalcite. It was reported that zincian malachite and aurichalcite are stable up to $270{ }^{\circ} \mathrm{C}$ and $360^{\circ} \mathrm{C}$, correspondingly [14,15]. When the calcination temperature was increased to $350{ }^{\circ} \mathrm{C}$, the zincian malachite and aurichalcite crystalline domains present in the CuZn catalyst precursor decomposed completely and the $\mathrm{CuO}$ and $\mathrm{ZnO}$ crystalline particles were formed. A further increase in the calcination temperature to $500{ }^{\circ} \mathrm{C}$ did not change the phase composition of the catalyst anymore, i.e., the $\mathrm{CuZn}-500 \mathrm{AS}$ sample consisted exclusively of a mixture of $\mathrm{CuO}$ and $\mathrm{ZnO}$. However, the intensity of the XRD reflexes notably increased, suggesting a growth of the crystallites size of both $\mathrm{CuO}$ and $\mathrm{ZnO}$.

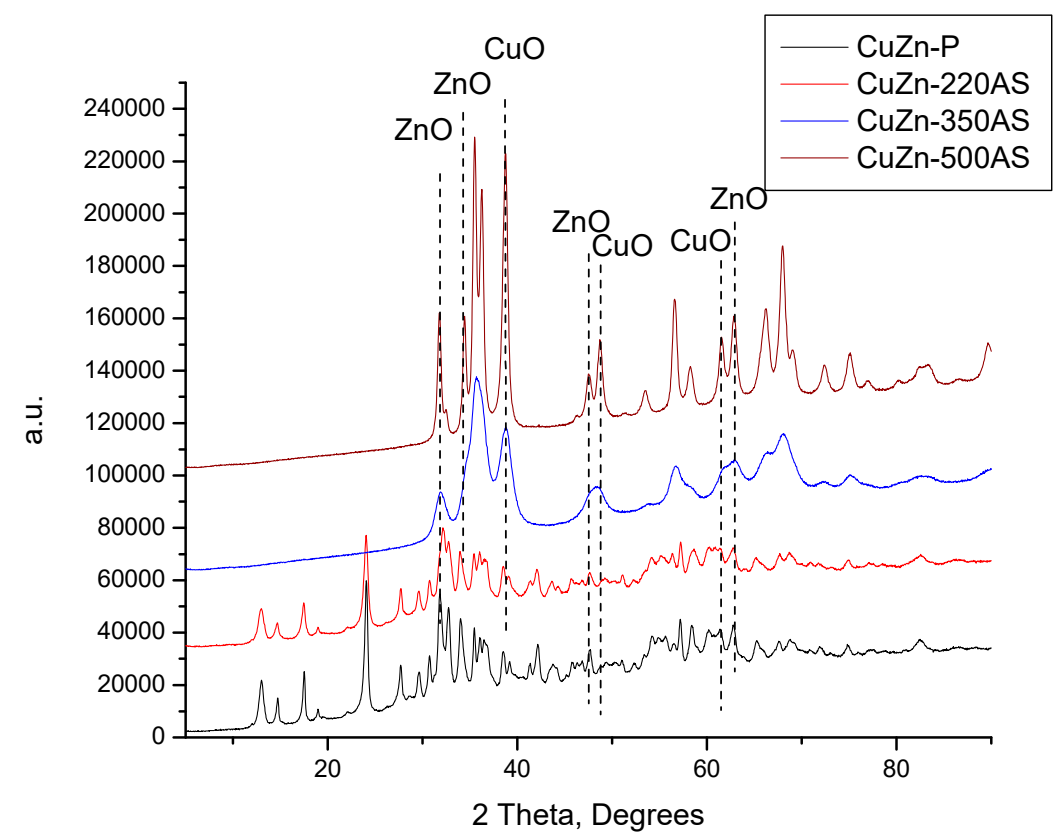

Figure 1. The XRD patterns of the catalysts prepared by the treatment of the $\mathrm{CuZn}$ precursor in static air at 220,350 , and $500{ }^{\circ} \mathrm{C}$.

The XRD patterns of the catalysts prepared by calcination in nitrogen again at temperatures 220 , 350 , and $500{ }^{\circ} \mathrm{C}$ were compared with the XRD pattern of the catalyst precursor in Figure 2. Unlike in the case of treatment in static air at $220^{\circ} \mathrm{C}$, the thermal treatment of the $\mathrm{CuZn}-\mathrm{P}$ in a nitrogen atmosphere at $220^{\circ} \mathrm{C}$ (underflow conditions) resulted in a change in the phase composition of the prepared catalyst sample $(\mathrm{CuZn}-220 \mathrm{~N})$. Although the reflexes of zincian malachite and aurichalcite 
are still present (Figure 2), they are accompanied by the reflexes of $\mathrm{CuO}$ and $\mathrm{ZnO}$. This evidences that the thermal decomposition of the initial crystalline phases has started under these calcination conditions. This difference can be explained by the different experimental setups, in particular, by the flow conditions or the partial local overheating of the precursor sample inside the autoclave (the sample is in contact with the autoclave wall while the thermocouple measuring the temperature is not). An increase in the treatment temperature to $350{ }^{\circ} \mathrm{C}$ resulted in a total disappearance of the reflexes of zincian malachite and aurichalcite accompanied by an increase in the intensity of the reflexes of $\mathrm{CuO}$ and $\mathrm{ZnO}$. Additionally, the reflexes belonging to $\mathrm{Cu}_{2} \mathrm{O}$ and $\mathrm{Cu}$ were identified in the XRD pattern of CuZn-350N as well (Figure 2). Because of the significant overlapping of the XRD reflexes of the different phases, only several characteristic reflexes are shown in Figure 2.

$$
\begin{aligned}
2 \mathrm{Cu}_{2} \mathrm{CO}_{3}(\mathrm{OH})_{2} & \rightarrow 4 \mathrm{CuO}+2 \mathrm{CO}_{2}+2 \mathrm{H}_{2} \mathrm{O} \\
2 \mathrm{CO}_{2} & \rightarrow 2 \mathrm{CO}+\mathrm{O}_{2} \\
4 \mathrm{CuO}+2 \mathrm{CO} & \rightarrow 2 \mathrm{Cu}_{2} \mathrm{O}+2 \mathrm{CO}_{2}
\end{aligned}
$$

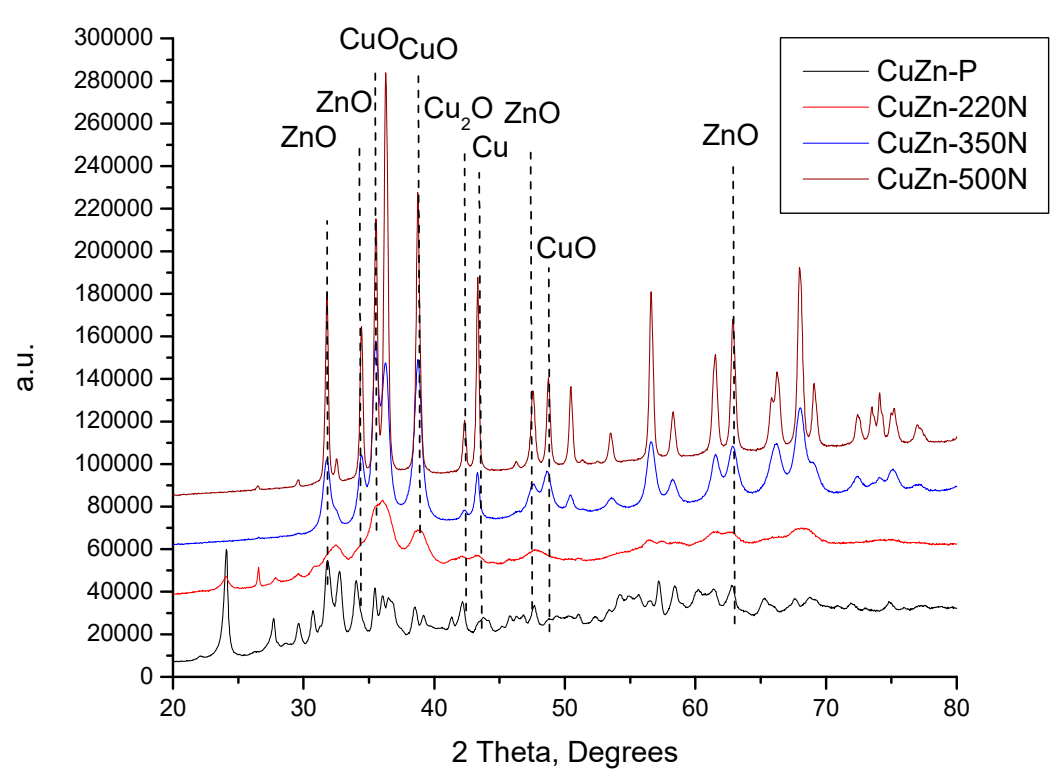

Figure 2. The XRD patterns of catalysts prepared by the treatment of the $\mathrm{CuZn}$ precursor in flowing nitrogen at 220,350 , and $500{ }^{\circ} \mathrm{C}$.

The exclusive formation of $\mathrm{CuO}$ resulting from the calcination of malachite in air (Equation (1)) and the possible formation of $\mathrm{Cu}_{2} \mathrm{O}$ during the calcination of malachite in an inert atmosphere was reported previously [15]. It was explained by $\mathrm{CO}_{2}$ decomposition to $\mathrm{CO}$ and subsequent reduction of $\mathrm{CuO}$ by $\mathrm{CO}$ (Equations (2) and (3)) [16]. The decomposition of both zincian malachite, and aurichalcite in nitrogen, by analogy with malachite, can be expected to yield $\mathrm{Cu}_{2} \mathrm{O}$ in addition to $\mathrm{CuO}$. If $\mathrm{CuO}$ is reduced by $\mathrm{CO}$ originating from $\mathrm{CO}_{2}$ to $\mathrm{Cu}_{2} \mathrm{O}$, the consecutive reduction step, i.e., the reduction of $\mathrm{Cu}_{2} \mathrm{O}$ to $\mathrm{Cu}$, is plausible as well. A further increase in the treatment temperature to $500{ }^{\circ} \mathrm{C}$ did not change the phase composition of the catalyst anymore, but the intensity of reflexes of all phases increased substantially due to the increased crystallite size of all phases. With a closer inspection of Figure 2, it can be established that the intensity of the reflexes corresponding to $\mathrm{Cu}_{2} \mathrm{O}$ and $\mathrm{Cu}$ increased more than those belonging to $\mathrm{CuO}$ and $\mathrm{ZnO}$ (Figure 2).

Finally, the catalyst precursor was also treated in flowing hydrogen at 220,350 , and $500{ }^{\circ} \mathrm{C}$. The resulting XRD patterns are shown in Figure 3 together with the XRD pattern of the catalyst precursor. In contrast to the treatment in air and nitrogen at $220^{\circ} \mathrm{C}$, there are no reflexes of the initial hydroxycarbonate phases in the XRD pattern of the $\mathrm{CuZn}-220 \mathrm{H}$, i.e., a catalyst obtained by treatment 
in a hydrogen atmosphere at $220^{\circ} \mathrm{C}$. Instead, low-intensive reflexes of $\mathrm{ZnO}, \mathrm{CuO}, \mathrm{Cu}_{2} \mathrm{O}$, and $\mathrm{Cu}$ appeared (Figure 3). As the treatment temperature increased from $220^{\circ} \mathrm{C}$ to $500{ }^{\circ} \mathrm{C}$, the intensity of the reflexes of the oxidic $\mathrm{Cu}$ phases declined while that of the metallic copper substantially increased (Figure 3). Simultaneously, the intensity of the reflexes of $\mathrm{ZnO}$ also increased. This can be attributed to the increase in the crystallite size of $\mathrm{ZnO}$ and $\mathrm{Cu}$ (discussed below) and to the gradual reduction of the oxidic $\mathrm{Cu}$ phases to metallic $\mathrm{Cu}$.

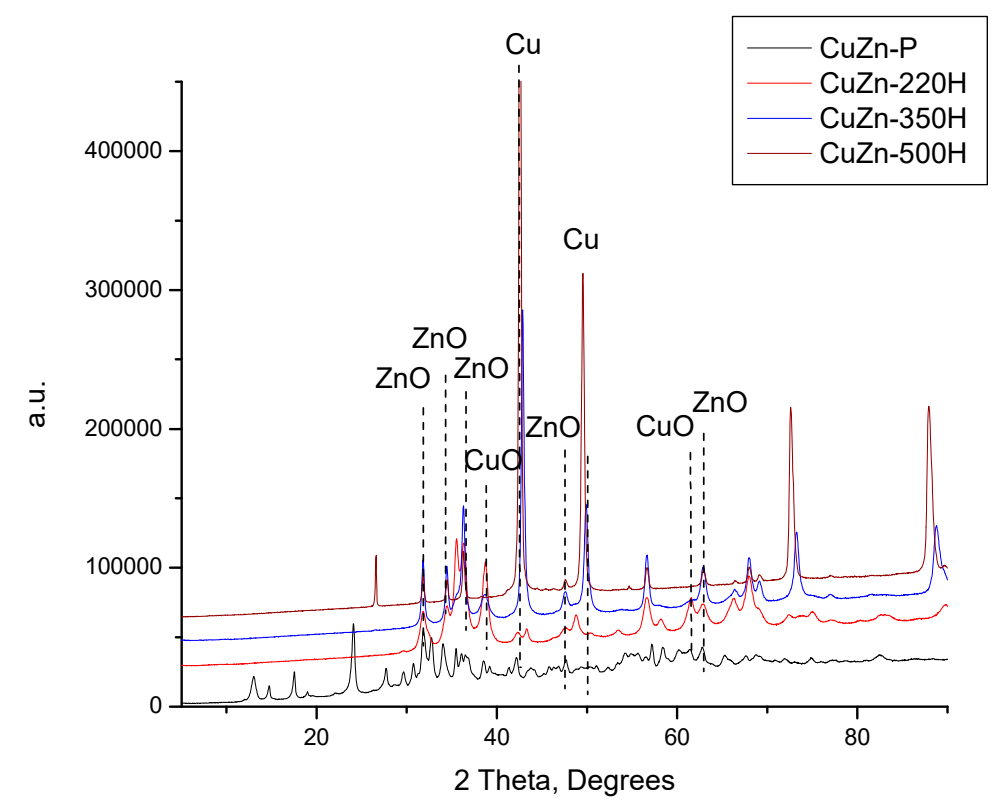

Figure 3. The XRD patterns of catalysts prepared by the treatment of the $\mathrm{CuZn}$ precursor in flowing hydrogen at 220,350 , and $500^{\circ} \mathrm{C}$.

The XRD results demonstrate that $220^{\circ} \mathrm{C}$ is a sufficient temperature to completely decompose hydroxycarbonates (zincian malachite and aurichalcite) in a hydrogen atmosphere, but not in air or nitrogen atmospheres. The lowered thermal stability of both hydroxycarbonate phases may be a consequence of a direct reduction of the hydroxycarbonate $\mathrm{Cu}$ species in zincian malachite and/or aurichalcite structures according to the proposed overall reaction (Equation (4)). This conclusion is further corroborated by the observed partial destruction of the hydroxycarbonate phase under nitrogen at $220^{\circ} \mathrm{C}$. The partial destruction is caused by the transformation of the inert atmosphere into a partially reducing atmosphere due to the formation of $\mathrm{CO}$ during the treatment.

$$
2\left(\mathrm{Cu}_{0.8} \mathrm{Zn}_{0.2}\right)_{2} \mathrm{CO}_{3}(\mathrm{OH})_{2}+3.2 \mathrm{H}_{2} \rightarrow 3.2 \mathrm{Cu}+0.8 \mathrm{ZnO}+\mathrm{CO}_{2}+5.2 \mathrm{H}_{2} \mathrm{O}
$$

Nevertheless, Figure 3 also evidences that $\mathrm{CuZn}-220 \mathrm{H}$ still contained $\mathrm{CuO}$ in its composition after the calcination step (it can be considered as a reduction step at the same time), which is another distinctive feature of the experiment performed in hydrogen at $220^{\circ} \mathrm{C}$. This is rather unexpected since the reduction of $\mathrm{CuO}$ to metallic copper in $\mathrm{CuO} / \gamma-\mathrm{Al}_{2} \mathrm{O}_{3}$ [17] or in $\mathrm{CuO} / \mathrm{ZnO}$ [11] occurred at temperatures around $200{ }^{\circ} \mathrm{C}$. On the other hand, the reduction of $\mathrm{Cu}^{2+}$ in bulky $\mathrm{CuO}$ was reported to occur at $300{ }^{\circ} \mathrm{C}$ [11]. It was proposed that the low-temperature reduction of $\mathrm{CuO}$ to metallic $\mathrm{Cu}$ took place for highly dispersed copper oxide species while the bulky $\mathrm{CuO}$ was reduced at higher temperatures $[15,17]$. The presence of oxidic $\mathrm{Cu}$ species in $\mathrm{CuZn}-220 \mathrm{H}$ allows for the assumption that the treatment conditions considerably influenced the properties (oxidation state, dispersion, etc.) of the $\mathrm{Cu}$ atoms in the resulting catalyst sample. Indeed, dedicated experiments showed (Figure A1) that the treatment of the CuZn-350AS sample (which is a mixture of $\mathrm{ZnO}$ and $\mathrm{CuO}$ phases; see Figure 1) in a hydrogen atmosphere at $220^{\circ} \mathrm{C}$ resulted in the total reduction of copper oxide to metallic copper. Moreover, the exclusive presence of the reflexes of metallic copper, i.e., without any oxidic phases 
detected suggests that these metallic domains are not susceptible to an easy re-oxidation in the air. In contrast, the treatment of CuZn-P firstly in the air at $220^{\circ} \mathrm{C}$ (yielding the CuZn-220AS sample) and then in hydrogen at the same temperature (Figure A1) resulted in the decomposition of zincian malachite and aurichalcite structures. The XRD pattern of CuZn-220AS-220H contained reflexes of $\mathrm{CuO}$ together with reflexes of metallic $\mathrm{Cu}$ at very low intensities. Thus, the existence of oxidic copper domains in the sample after a reductive treatment at $220{ }^{\circ} \mathrm{C}$ is undoubtedly a consequence of the sample preparation under specific conditions and their sequence.

The collected XRD patterns allowed for the calculation of the crystallite size of all phases detected in the catalysts using the Scherrer equation [18]. The sizes of the crystallites of zinc and copper compounds were calculated from the width of the corresponding diffraction lines that did not overlap with the lines belonging to other phases. As expected, the crystallite size depended on the pretreatment temperature and, more interestingly, on the calcination atmosphere (Table 1).

Table 1. The crystallite size of $\mathrm{ZnO}, \mathrm{CuO}, \mathrm{Cu}_{2} \mathrm{O}$, and $\mathrm{Cu}$ present in the catalysts prepared by calcination in different atmospheres at different temperatures.

\begin{tabular}{|c|c|c|c|c|}
\hline \multirow{2}{*}{ Sample } & \multicolumn{4}{|c|}{ Particle Size, nm (2 Theta, Degrees) } \\
\hline & $\mathrm{ZnO}(31.7)$ & $\mathrm{CuO}(38.7)$ & $\mathrm{Cu}_{2} \mathrm{O}(42.3)$ & $\mathrm{Cu}(43.3)$ \\
\hline 220AS & $\mathrm{ND}^{1}$ & ND & ND & ND \\
\hline $220 \mathrm{AS}-220 \mathrm{H}^{2}$ & 7.3 & 7.3 & 8.7 & 10.2 \\
\hline 350AS & 5.1 & 7.7 & ND & ND \\
\hline 350 AS- $220 \mathrm{H}^{2}$ & 12.5 & ND & ND & 18.1 \\
\hline 500AS & 15.8 & 11.9 & ND & ND \\
\hline $220 \mathrm{~N}$ & 5.9 & 6.5 & 7.9 & 11.5 \\
\hline $350 \mathrm{~N}$ & 11 & 10.3 & 21 & 22.2 \\
\hline $500 \mathrm{~N}$ & 33.9 & 25.5 & 36 & 46.1 \\
\hline $220 \mathrm{H}$ & 9.8 & 9.2 & 11.2 & 18.1 \\
\hline $350 \mathrm{H}$ & 20 & 16.7 & ND & 23.4 \\
\hline $500 \mathrm{H}$ & 34.7 & ND & ND & 33.2 \\
\hline
\end{tabular}

Due to the increasing pretreatment temperature in static air from $350{ }^{\circ} \mathrm{C}$ to $500{ }^{\circ} \mathrm{C}$, the size of the $\mathrm{ZnO}$ and $\mathrm{CuO}$ crystallites increased from $5.1 \mathrm{~nm}$ and $7.7 \mathrm{~nm}$ to 15.8 and $11.9 \mathrm{~nm}$, correspondingly. When the pretreatment was performed in a non-oxidizing atmosphere, either in nitrogen or in hydrogen, the size of the produced oxidic particles was larger compared to the corresponding experiments in static air (Table 1). Moreover, at a given temperature, the size of $\mathrm{ZnO}$ crystallites was larger in the catalysts prepared by calcination in nitrogen or hydrogen in comparison with those prepared in air (Table 1). This allows for the suggestion of a mutual stabilization of the $\mathrm{CuO}$ and $\mathrm{ZnO}$ domains if these are in intimate contact with each other. This conclusion is further supported by the larger size of the $\mathrm{Cu}$ crystallites obtained by direct reduction (calcination in hydrogen) than those obtained by calcination in air followed by reduction at $220^{\circ} \mathrm{C}$ (Table 1). In addition, the size of metallic copper increased in comparison with the size of its oxidic precursors which indicates copper sintering during the reduction step. It is interesting to note that (i) the catalysts reduced after previous calcination in air, (ii) catalysts obtained by calcination in nitrogen (copper formed due to reduction by in-situ formed $\mathrm{CO}$ ) and (iii) catalysts prepared by calcination in hydrogen (i.e., by direct reduction) exhibit a common linear dependency between the $\mathrm{CuO}$ crystallite size and the resulting $\mathrm{Cu}$ crystallite size (Figure 4). This might indicate that $\mathrm{Cu}$ is formed during the calcination of the hydroxycarbonate precursors either via $\mathrm{CuO}$ or that the formation of both crystallites is related in another way. 


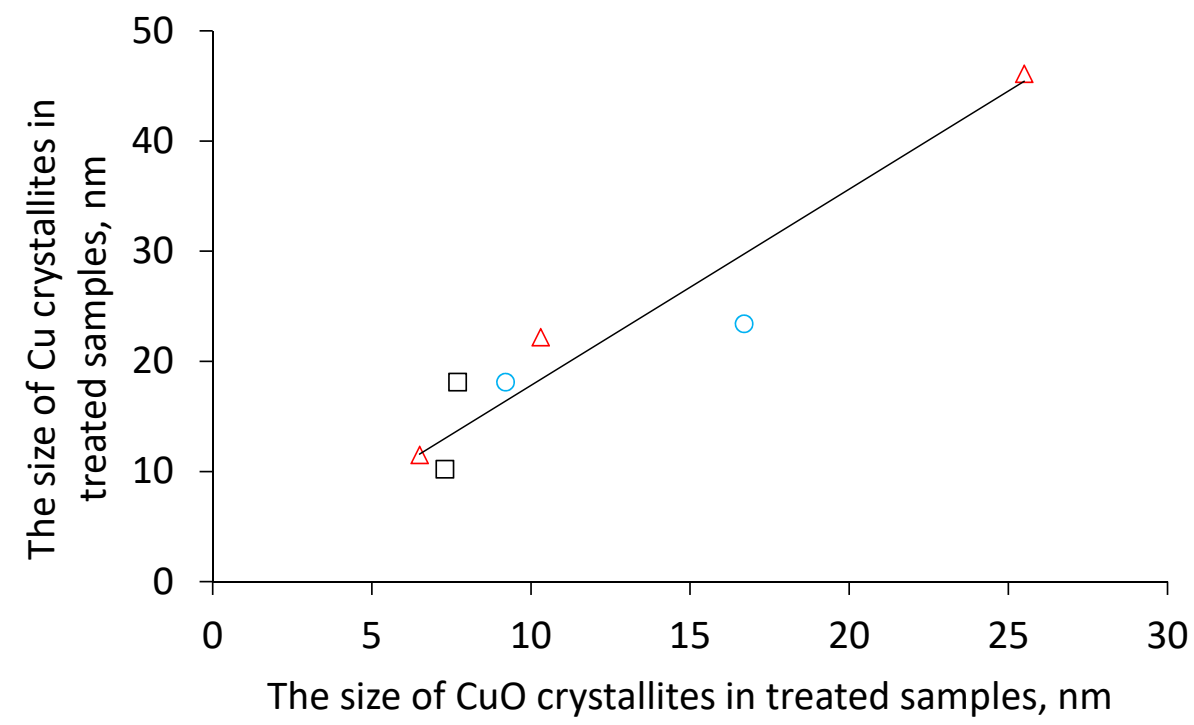

Figure 4. A relationship between the $\mathrm{CuO}$ and $\mathrm{Cu}$ crystallites size in catalyst samples prepared by calcination in air $(\square)$, nitrogen $(\Delta)$ and hydrogen $(\bigcirc)$ at different temperatures.

The calcination atmosphere and temperature significantly affected the textural properties of the final catalysts. The results are summarized in Table 2. Among the samples calcined in air, CuZn-350AS possessed the best textural properties with respect to the BET surface, the external surface, pore volume, and average nanoparticle size. The CuZn-220AS had only slightly worse parameters compared to CuZn-350AS despite their substantially different phase composition. This could be attributed to the fact that $\mathrm{CuZn-220AS}$ was a mixture of hydroxycarbonates rather than of oxides. The increase in the calcination temperature to $500{ }^{\circ} \mathrm{C}$ resulted in a dramatic decrease in the textural properties of CuZn-500AS. On the other hand, the trend in the change in all characteristics observed for the samples prepared in nitrogen and hydrogen is more unambiguous. The BET surface, the external surface, and the pore volume substantially decreased while the average nanoparticle size, accordingly, increased with the increasing calcination temperature. It should also be noted that the samples prepared in hydrogen had worse adsorption characteristics, except for the micropore surface, compared with the similar samples prepared in nitrogen. Besides, Table 2 evidences that the pore diameter of differently prepared catalysts was approximately the same in the range of 13-39 nm and showed no dependence on either the atmosphere or calcination temperature.

Table 2. The textural properties of the CuZn catalysts prepared by the calcination of the CuZn precursor in air, nitrogen, and hydrogen at 220,350 , and $500^{\circ} \mathrm{C}$.

\begin{tabular}{|c|c|c|c|c|c|c|}
\hline \multirow{2}{*}{ Sample } & \multirow{2}{*}{$\begin{array}{l}\text { BET Surface, } \\
\mathrm{m}^{2} \cdot \mathrm{g}^{-1}\end{array}$} & \multicolumn{2}{|c|}{$\mathrm{t}$-Plot Surface, $\mathrm{m}^{2} \cdot \mathrm{g}^{-1}$} & \multirow{2}{*}{$\begin{array}{c}\text { BJH Pore } \\
\text { Volume, } \mathrm{cm}^{3} \cdot \mathrm{g}^{-1}\end{array}$} & \multirow{2}{*}{$\begin{array}{c}\text { BJH Pore } \\
\text { Diameter, nm }\end{array}$} & \multirow{2}{*}{$\begin{array}{c}\text { Average } \\
\text { Nanoparticle } \\
\text { Size, } \mathbf{n m}\end{array}$} \\
\hline & & Micropore & External & & & \\
\hline CuZn-220AS & 49 & 5.1 & 43.9 & 0.342 & 27 & 122 \\
\hline CuZn-350AS & 62 & 1.3 & 61.1 & 0.463 & 25 & 96 \\
\hline CuZn-500AS & 17 & 0.1 & 16.5 & 0.084 & 23 & 364 \\
\hline CuZn-220N & 65 & 0 & 78.3 & 0.4 & 21 & 89 \\
\hline CuZn-350N & 32 & 4.7 & 27.6 & 0.274 & 39 & 186 \\
\hline CuZn-500N & 8 & 0.8 & 7.5 & 0.021 & 13 & 722 \\
\hline $\mathrm{CuZn-220H}$ & 26 & 3.1 & 22.7 & 0.194 & 31 & 233 \\
\hline CuZn-350H & 14 & 0.6 & 13.5 & 0.089 & 27 & 423 \\
\hline CuZn-500H & $\mathrm{NM}^{1}$ & & & & & \\
\hline
\end{tabular}

${ }^{1}$ NM stands for not measured. 


\subsection{Activity and Selectivity of the Catalysts}

Figure 5 depicts the dependency of the DMA conversion on the pretreatment conditions (i.e., different calcination atmosphere and temperature) applied to the synthesized CuZn-P precursor. $\mathrm{CuZn-220AS}$ prepared by a mild heating in static air possessed a reasonable activity in the reaction with DMA; the DMA conversion reached $64 \%$ after $2 \mathrm{~h}$. When the calcination temperature was increased to $350{ }^{\circ} \mathrm{C}$, the catalytic performance of the catalyst further improved; the DMA conversion amounted to $78 \%$ after $2 \mathrm{~h}$ (Figure 5). The observed increase is in agreement with the improvement in the textural properties of CuZn-220AS and CuZn-350 AS (Table 2). Additionally, the phase composition of the calcined catalysts after reduction has to be considered as well. The catalyst CuZn-220AS, if exposed to hydrogen at $220^{\circ} \mathrm{C}$ for $2 \mathrm{~h}$, still contained $\mathrm{Cu}$ in the oxidic state (Figure 4, sample CuZn-220AS-220H). On the other hand, the XRD pattern of this catalyst after the reaction (will be discussed further) revealed the presence of only metallic $\mathrm{Cu}$ clusters. This suggests the occurrence of a subsequent reduction of the oxidic $\mathrm{Cu}$ species during the reaction. In contrast, the catalyst $\mathrm{CuZn}-350 \mathrm{AS}$ exclusively contained metallic $\mathrm{Cu}$ clusters after the reduction step, so no additional activation during the reaction was necessary. This difference in the state of $\mathrm{Cu}$ in the catalysts, although inexplicable at the moment, could explain the difference in the catalytic performance of CuZn-220AS and CuZn-350AS together with their different textural properties. A further increase in the calcination temperature in air to $500{ }^{\circ} \mathrm{C}$ resulted in a decrease in the activity of the catalyst $\mathrm{CuZn}-500 \mathrm{AS}$ with the DMA conversion of $43 \%$ after $2 \mathrm{~h}$ (Figure 5).

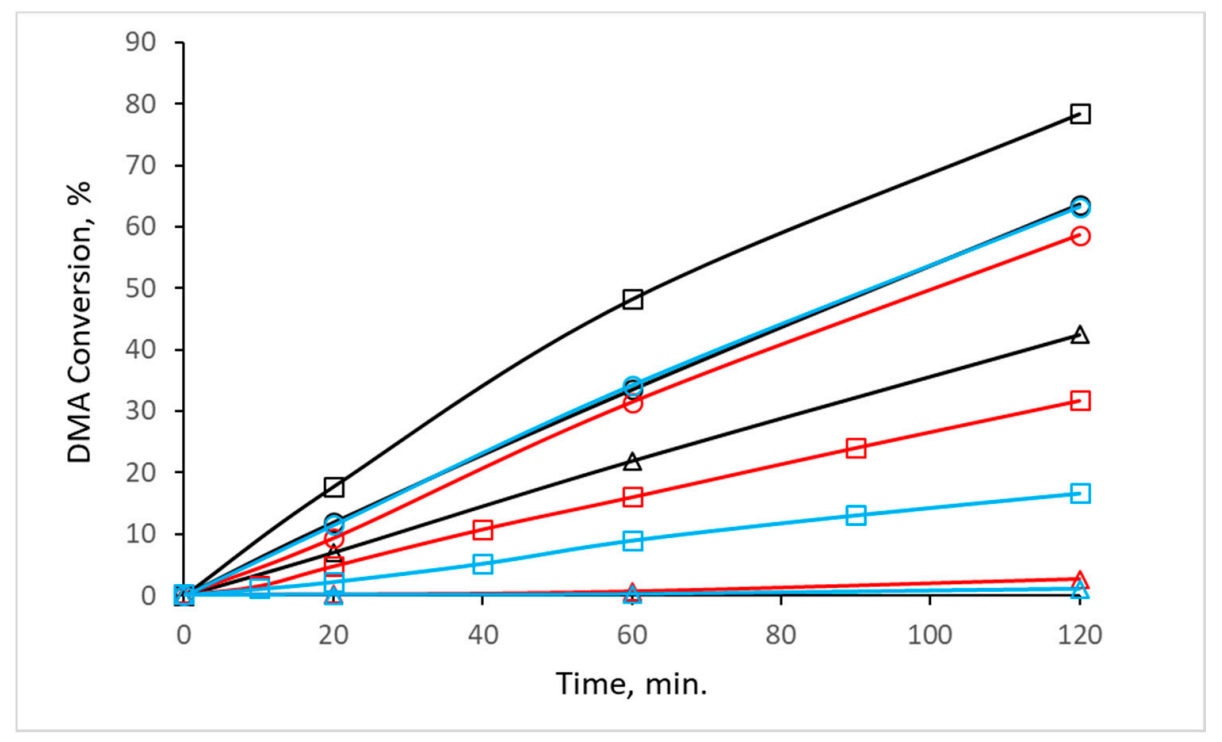

Figure 5. The DMA conversion observed on the $\mathrm{CuZn}$ catalysts in dependence on the temperature of their treatment in air (black line), $\mathrm{N}_{2}$ (red line), and $\mathrm{H}_{2}$ (blue line). Samples calcined at $\mathrm{T}=220^{\circ} \mathrm{C}(\bigcirc)$, $350{ }^{\circ} \mathrm{C}(\square), 500{ }^{\circ} \mathrm{C}(\Delta)$.

The observed decrease in conversion can be attributed to the increase in the size of the copper crystallites determined from the XRD patterns (Table 1). The increase in the calcination temperature caused an increase in the size of copper crystallites leading to a decrease in the number of available catalytically active centers. A similar dependence of the catalytic performance of $\mathrm{Cu}$-containing catalysts on the particle size of copper being influenced by the calcination temperature was also reported for the hydrogenolysis of ethyl acetate to ethanol [4]. In contrast, Peng Yuan et al. [5] observed an increase in the DMA conversion over a $\mathrm{Cu}-\mathrm{Zn}-\mathrm{Al}$ catalyst as the calcination temperature was increased from $400{ }^{\circ} \mathrm{C}$ to $500^{\circ} \mathrm{C}$.

The catalysts prepared by calcination in nitrogen and hydrogen also showed a trend of decreasing the DMA conversion with the increasing calcination temperature. For CuZn catalysts prepared by calcination in nitrogen, the DMA dropped significantly (from 59 to $3 \%$ ) when the calcination 
temperature was increased from $220^{\circ} \mathrm{C}$ to $500{ }^{\circ} \mathrm{C}$ (Figure 5). The effect of the hydrogen calcination atmosphere was even more pronounced. The DMA conversion decreased from $63 \%$ to a negligible $1 \%$ when the calcination temperature was increased from $220^{\circ} \mathrm{C}$ to $500{ }^{\circ} \mathrm{C}$. The physicochemical characterization of the catalysts allows the attributing of this behavior to the increase in the $\mathrm{Cu}$ crystallite size with increasing calcination temperature and to the worse textural properties of catalysts prepared by calcination at high temperatures. The dependence of the conversion on crystallite size is obvious when the DMA conversion is plotted as a function of $\mathrm{CuO}$ or $\mathrm{Cu}$ crystallites (Figures 6 and $\mathrm{A} 2$ ).

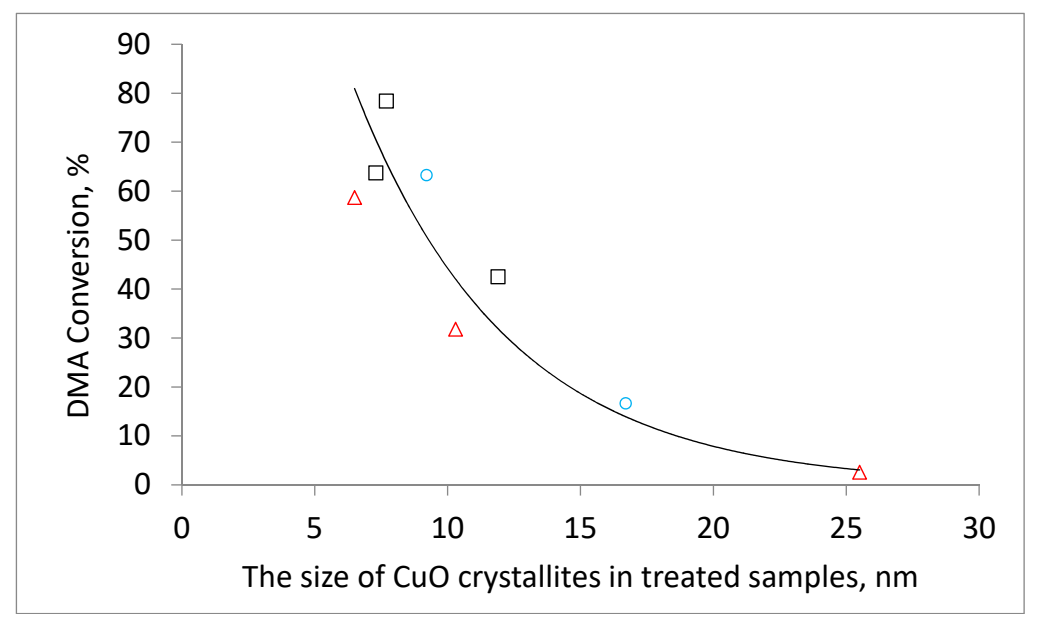

Figure 6. A correlation between the DMA conversion (after $120 \mathrm{~min}$. of the reaction) and the size of $\mathrm{CuO}$ crystallites in the prepared CuZn catalysts. $\square$ : calcined in air, $\Delta$ : calcined in nitrogen, $\bigcirc$ : calcined in hydrogen.

The observed correlation between the catalytic performance of CuZn catalysts prepared in the present study and the size of the $\mathrm{Cu}$ domains can be expected since the performance of the $\mathrm{Cu}$-containing catalysts in different reactions has been repeatedly shown to depend on copper particle size $[5,11,17]$. Nevertheless, the treatment of the starting precursor in air, on the one hand, and in nitrogen or hydrogen, on the other hand, introduces some unique (previously not described) features to the performance of the CuZn hydrogenolysis catalyst. Regardless of the atmosphere used, all catalysts which were thermally treated at $220^{\circ} \mathrm{C}$ exhibited approximately the same catalytic activity. The DMA conversion was in the range 59-64\% (Figure 5) despite their phase composition after calcination differing significantly (Table 1). Moreover, the comparison of catalytic results with the physicochemical properties of the prepared catalysts exhibits no clear correlation between the catalytic performance of the catalysts and their textural properties.

On the other hand, catalytic results suggest that the high DMA conversion over catalysts prepared at $220{ }^{\circ} \mathrm{C}$ is observed provided that the samples possess small-size copper crystallites (Table 1). An increase in the calcination temperature to $350{ }^{\circ} \mathrm{C}$ resulted in an increase in the DMA conversion to $78 \%$ for $\mathrm{CuZn}-350 \mathrm{AS}$ while the activity of $\mathrm{CuZn}-350 \mathrm{~N}$ and $\mathrm{CuZn} 350 \mathrm{H}$ markedly decreased. According to $\mathrm{XRD}, \mathrm{CuZn}-350 \mathrm{AS}$ represents a mixture of $\mathrm{ZnO}$ and $\mathrm{CuO}$ whereas the other samples contain notable amounts of $\mathrm{Cu}_{2} \mathrm{O}$ and $\mathrm{Cu}$ besides $\mathrm{CuO}$ and $\mathrm{ZnO}$. The crystallite size of $\mathrm{Cu}_{2} \mathrm{O}$ and $\mathrm{Cu}$ is significantly larger than that of $\mathrm{CuO}$ and $\mathrm{ZnO}$ and they are plausibly present as separate phases that are not in intimate contact with the $\mathrm{ZnO}$ phase. This difference in the phase composition of the samples allows for the suggestion that an intimate contact between the $\mathrm{CuO}$ and $\mathrm{ZnO}$ crystallites because of the thermal treatment could be an important factor that stabilizes the small size of the $\mathrm{Cu}$ domains. Consequently, a high activity of CuZn catalysts is achieved. When calcining in air, the increase in the calcination temperature from $220^{\circ} \mathrm{C}$ to $350{ }^{\circ} \mathrm{C}$ resulted in a complete destruction of the zincian malachite and aurichalcite structures. This led to an increased number of $\mathrm{CuO}$ and $\mathrm{ZnO}$ crystallites, thus, promoting the probability of close contact between the two phases. Additionally, the very small 
size of $\mathrm{ZnO}$ crystallites (Table 1) could also contribute to the high dispersion of the $\mathrm{CuO}$ domains. In contrast, the presence of the $\mathrm{Cu}_{2} \mathrm{O}$ and $\mathrm{Cu}$ crystallites in samples prepared in $\mathrm{N}_{2}$ and $\mathrm{H}_{2}$ reduced the probability of the necessary interaction between $\mathrm{CuO}$ and $\mathrm{ZnO}$. As a result, the number of potentially active sites formed on the interface between the $\mathrm{CuO}$ and $\mathrm{ZnO}$ domains after the reduction differs for catalysts prepared by the calcination in different atmospheres. Additionally, the existence of the said interfaces contributes to the stabilization of the $\mathrm{Cu}$ crystallites in $\mathrm{ZnO}$ surroundings. As a result, CuZn-350AS has a higher BET surface area, external surface, and pore volume with lower crystallites size values than $\mathrm{CuZn}-350 \mathrm{~N}$ and $\mathrm{CuZn}-350 \mathrm{H}$. As can be deduced from Table 1, the absence of intimate $\mathrm{CuO}-\mathrm{ZnO}$ contact resulted in a more facile sintering of both the $\mathrm{Cu}$ and $\mathrm{Zn}$ domains at elevated temperatures. Consequently, the DMA conversion over CuZn-350AS was the highest

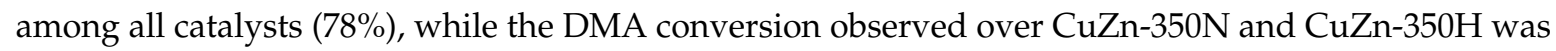
much lower, i.e., $32 \%$ and $17 \%$, respectively. The significantly lower conversion over $\mathrm{CuZn}-350 \mathrm{H}$ in comparison with $\mathrm{CuZn}-350 \mathrm{~N}$ is the consequence of a more extensive reduction of $\mathrm{CuZn}-350 \mathrm{H}$ during calcination and, hence, the lower probability to stabilize the $\mathrm{CuO}$ domains by intimate contact with $\mathrm{ZnO}$. Consequently, the $\mathrm{CuO}$ and $\mathrm{ZnO}$ crystallites are approximately $17-20 \mathrm{~nm}$ large in $\mathrm{CuZn}-350 \mathrm{H}$ whereas only 10-11 $\mathrm{nm}$ in CuZn-350N (Table 1).

As reported previously [6], CuZn catalysts catalyze not only hydrogenolysis, but highermolecular-weight products originating from transesterification reactions between DMA, 1,6-hexanediol (1,6-HDO), and partially hydrogenolyzed DMA (1HMEol) are also formed. These transesterification products consist of products with two $\mathrm{C}_{6}$ backbones in their molecules (denoted $\mathrm{H} 2$ ) or with three $\mathrm{C}_{6}$ backbones in their molecules (denoted H3). Thus, the selectivity to and yields of different products allow for obtaining additional important information on the performance of catalysts particularly with respect to the origins of the transesterification activity of the CuZn catalysts. Figure 7 depicts the selectivity towards reaction products formed by DMA hydrogenolysis over catalysts prepared by the thermal activation of CuZn-P in air. Regardless, the calcination temperature selectivity to the reaction products observed over the three CuZn-TAS catalysts followed the same trend as a function of DMA conversion. To maintain readability of the graph, the selectivities over all $\mathrm{CuZn}$-TAS catalysts were not distinguished according to the calcination temperature (Figure 7).

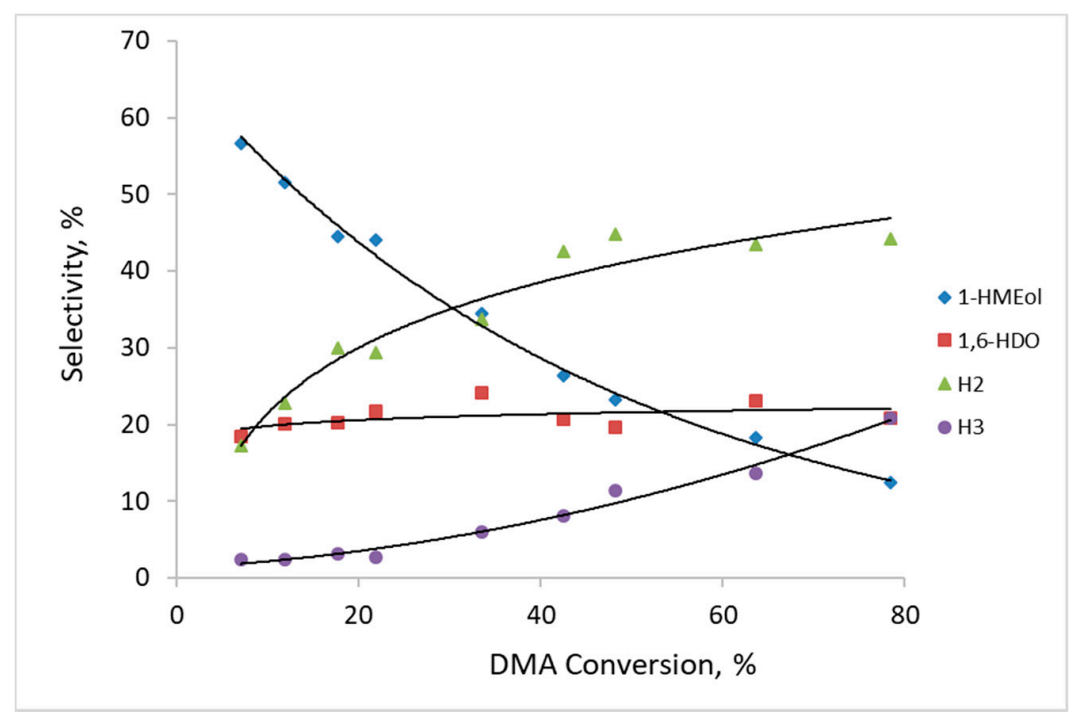

Figure 7. The change of selectivity to the reaction products in dependence on the DMA conversion observed over the catalysts prepared by the calcination of the precursor, CuZn-P, in the air at 220, 350 , and $500{ }^{\circ} \mathrm{C}$. $1 \mathrm{HMEol}$ is methyl 6-hydroxyhexanoate; 1,6-HDO is hexane-1,6-diol; H2 is the sum of 6-methoxy-6-oxohexyl methyl adipate, 6-hydroxyhexyl methyl adipate, and 6-hydroxyhexyl 6-hydroxyhexanoate; and H3 is the sum of bis(6-methoxy-6-oxohexyl) adipate, 6-hydroxyhexyl (6-methoxy-6-oxohexyl) adipate, and bis(6-hydroxyhexyl) adipate. 
The composition of the main reaction products and their tendency to change with the increasing DMA conversion is consistent with the results from our previous work [6]. 1HMEol is evidently a primary product formed by the hydrogenolysis of only one ester group of the two present in the DMA. Its selectivity approached $100 \%$ at DMA conversion close to zero. Subsequently, 1HMEol can be transformed either by the hydrogenolysis of the second ester group yielding 1,6-HDO or by participating in transesterification reactions yielding bulky $\mathrm{H} 2$ and $\mathrm{H} 3$ molecules (for structures and chemical names, see Scheme 1). The hydrogenolysis of the second ester group in the DMA, i.e., the ester group in $1 \mathrm{HMEol}$, also proceeded very fast on the catalysts prepared by calcination in air. Consequently, the selectivity to $1,6-\mathrm{HDO}$ reached $20 \%$ at a DMA conversion as low as $12 \%$. However, once $1 \mathrm{HMEol}$ and 1,6-HDO were formed, the transesterification reactions involving DMA, 1HMEol, and / or 1,6-HDO became possible and resulted in a formation of bulky compounds with either two or three "hexane backbones" in their molecule, denoted as H2 and H3 (for structures, see Scheme 1). During the reaction, the formation of the heavy $\mathrm{H} 2$ and $\mathrm{H} 3$ compounds became prevalent. Therefore, at DMA conversion of about $80 \%$, the selectivity to $\mathrm{H} 2$ and $\mathrm{H} 3$ attained $44 \%$ and $21 \%$, respectively. In addition, other reaction products, including cyclic ones (due to intramolecular transesterification), have also been identified among the reaction products. Their amount was small and they were excluded from further consideration. It can be inferred that the transesterification reactions are preferred to the second ester group hydrogenolysis under the studied reaction conditions as the selectivity to 1,6-HDO increased at a much more moderate rate with the increasing DMA conversion than the selectivity to the $\mathrm{H} 2$ and $\mathrm{H} 3$ products.

It has been reported that the hydrogenolysis of both ester functions in the DMA molecule does not occur at the same rate [5,19]. Hence, a ratio between the selectivities to HDO and the sum of the $\mathrm{H} 2$ and $\mathrm{H} 3$ products can help in evaluating the contribution of different reaction routes to the total composition of the reaction products. The ratio $\mathrm{S}_{\mathrm{HDO}} / \mathrm{S}_{\mathrm{H} 2+\mathrm{H} 3}$ observed for CuZn catalysts calcined in air varied only slightly for the three calcination temperatures; it was in the range of 0.61-0.94 at a DMA conversion $\approx 10 \%$. This shows that the ratio between the active sites responsible for hydrogenolysis and transesterification, respectively, is approximately the same in these catalysts and does not change significantly due to different calcination temperature in air.

In the case of catalysts prepared by calcination in nitrogen and hydrogen at $220^{\circ} \mathrm{C}(\mathrm{CuZn}-220 \mathrm{~N}$ and $\mathrm{CuZn}-220 \mathrm{H}$, respectively), the maximum yield of $1 \mathrm{HMEol}$ reached ca. $10-12 \%$ at a DMA conversion of ca. $40 \%$. The same maximum yield of $1 \mathrm{HMEol}$ was also obtained for all three catalysts prepared by calcination in air (Figure $8(1 \mathrm{~A}, 2 \mathrm{~A}, 3 \mathrm{~A})$ ), suggesting that all catalysts prepared by calcination at $220{ }^{\circ} \mathrm{C}$ have a similar distribution of the $\mathrm{Cu}$ active sites regardless of the calcination atmosphere. Consequently, the $\mathrm{S}_{\mathrm{HDO}} / \mathrm{S}_{\mathrm{H} 2+\mathrm{H} 3}$ calculated for $\mathrm{CuZn}-220 \mathrm{~N}$ and $\mathrm{CuZn}-220 \mathrm{H}$ at DMA conversion $\approx 10 \%$ was 0.77 and 0.7 , correspondingly, which is within the range of values observed for the catalysts prepared by the calcination in air. Similar to the air-calcined CuZn catalysts, the selectivity to $\mathrm{H} 2$ and $\mathrm{H} 3$ increased markedly with the increase in the DMA conversion for CuZn-220N and CuZn-220H catalysts, implying the secondary nature of $\mathrm{H} 2$ and $\mathrm{H} 3$ formation.

A different selectivity character was observed in the case of samples prepared by the calcination of the CuZn-P precursor at 350 and $500{ }^{\circ} \mathrm{C}$ in nitrogen or hydrogen. The yields of the 1 HMEol were minor-the maximum yield of $1 \mathrm{HMEol}$ was achieved over $\mathrm{CuZn}-350 \mathrm{~N}$ and amounted to $2 \%$ at a DMA conversion of $30 \%$. This is significantly less than the samples calcined at $220{ }^{\circ} \mathrm{C}$ in nitrogen, hydrogen, or in air (ca. $10-12 \%$ yield at a $30 \%$ DMA conversion). The 1,6-HDO yields were virtually $0 \%$, which is again dramatically lower than the other catalysts that yielded $4-6 \% \mathrm{HDO}$ at comparable conversions (Figure 8(1B,2B,3B)). Surprisingly, the esters (H2 and H3 products) requiring 1HMEol and/or HDO in addition to DMA were the prevailing reaction products. At a given conversion, their yield significantly exceeded the yield of esters formed over the CuZn catalysts calcined at $220{ }^{\circ} \mathrm{C}$ (in all atmospheres) and all catalysts calcined in air (i.e., calcined at 220,350 , or $500^{\circ} \mathrm{C}$ ); see Figure $8(1 \mathrm{C}, 2 \mathrm{C}, 3 \mathrm{C}, 1 \mathrm{D}, 2 \mathrm{D}, 3 \mathrm{D})$. It can be inferred that the calcination temperature in a non-oxidizing atmosphere had a severe impact on the hydrogenolysis activity of the CuZn catalysts, as the $\mathrm{S}_{\mathrm{HDO}} / \mathrm{S}_{\mathrm{H} 2+\mathrm{H} 3}$ dropped to values as low 
as 0.002 for catalysts calcined at $350{ }^{\circ} \mathrm{C}$ in $\mathrm{N}_{2}$ or $\mathrm{H}_{2}$. The results, thus, provide strong evidence that the hydrogenolysis of the methyl ester function and the transesterification reaction leading to the formation of bulky molecules, $\mathrm{H} 2$ and $\mathrm{H} 3$, occur on different active sites. Obviously, both the calcination atmosphere and temperature strongly affect the performance of the CuZn catalysts. The identification (and possibly also quantification) of the active sites, however, remains a task for forthcoming studies.
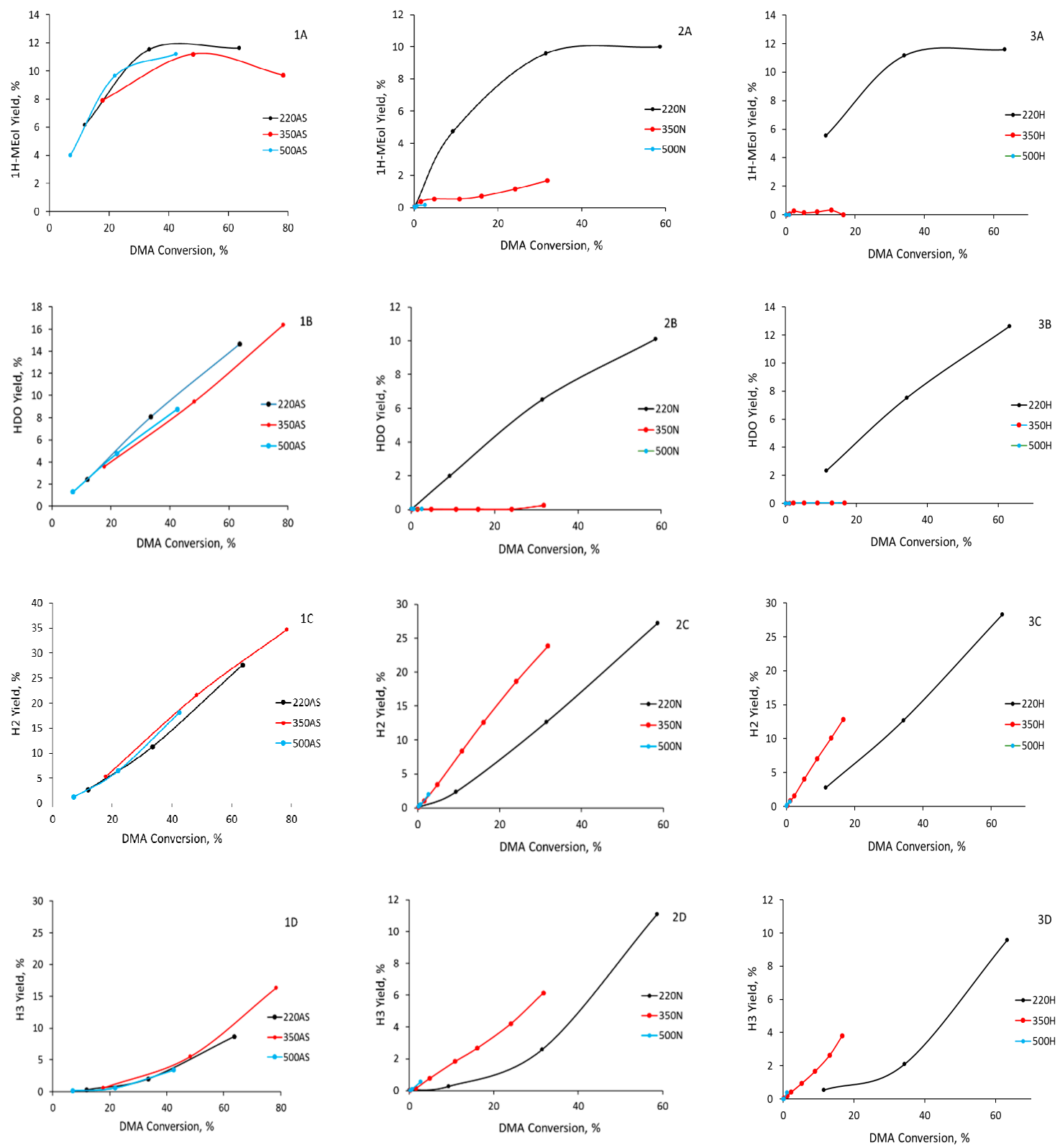

Figure 8. The change of the yield of reaction products (A: 1HMEol, B: HDO, C: H2, D: H3) with a dependence on the DMA conversion observed over the samples prepared by the thermal treatment of CuZn-P in air (1), nitrogen (2) and hydrogen (3).

\section{Materials and Methods}

A CuZn precursor with the copper/zinc molar ratio of 1.6 was prepared by a co-precipitation method based on the neutralization of a starting acidic solution with a basic precipitating agent. For the synthesis of the precursor, a glass beaker was filled with $200 \mathrm{~mL}$ of distilled water and heated to $\mathrm{T}=60{ }^{\circ} \mathrm{C}$ under stirring at $600 \mathrm{RPM}$. An aqueous solution $(0.5 \mathrm{M})$ containing $\mathrm{Cu}\left(\mathrm{NO}_{3}\right)_{2} \cdot 3 \mathrm{H}_{2} \mathrm{O}$ (99.0\%, Penta, s.r.o., Prague, Czech Republic), $\mathrm{Zn}\left(\mathrm{NO}_{3}\right)_{2} \cdot 6 \mathrm{H}_{2} \mathrm{O}$ (99.6\%, Lach:Ner, s.r.o., Neratovice, 
Czech Republic), and an aqueous solution (0.5 M) of $\mathrm{Na}_{2} \mathrm{CO}_{3}$ (99.4\%, Lach:Ner, s.r.o., Neratovice, Czech Republic) used as the precipitant were dosed simultaneously dropwise to keep the $\mathrm{pH}$ value in the beaker in the range of $7 \pm 0.1$. The temperature and stirring rate were kept constant at $60^{\circ} \mathrm{C}$ and 600 RPM, correspondingly, during the precipitation. The resulting suspension was aged under stirring for $90 \mathrm{~min}$ which caused an increase in the $\mathrm{pH}$ value to 7.6-7.7. The prepared precipitate was then filtered using a vacuum pump, washed with plenty of distilled water, and finally dried at $70{ }^{\circ} \mathrm{C}$ overnight.

To prepare a series of catalysts for the investigations, the starting CuZn precursor denoted as CuZn-P (fine powder, $1 \mathrm{~g}$ used for each experiment) was thermally treated either in an oven in static open air or in a Parr autoclave in a flow of either nitrogen (99.99\% SIAD Czech, s.r.o., Prague, Czech Republic) or hydrogen (99.9\% SIAD Czech, s.r.o, Prague, Czech Republic). The thermal activation of the precursor in each of the gas atmospheres was performed at 220,350 , and $500{ }^{\circ} \mathrm{C}$ for $2 \mathrm{~h}$. The prepared samples were denoted as CuZn-TAS, CuZn-TN, and CuZn-TH, where $T$ stands for the temperature of the heat treatment (calcination) while AS, $\mathrm{N}$, and $\mathrm{H}$ stand for static air, flowing nitrogen and hydrogen used as a gas atmosphere, respectively. For example, CuZn-350AS denotes a catalyst prepared by the calcination of the precursor, $\mathrm{CuZn}-\mathrm{P}$, at $350{ }^{\circ} \mathrm{C}$ in an air atmosphere.

The copper and zinc content in the as-prepared CuZn-P sample were determined by XRF using a spectrometer ARL 9400 XP equipped with a rhodium lamp (Thermo ARL, Ecublens, Switzerland). The phase composition of the CuZn catalysts and the size of the crystallites of the relevant phases present in the catalysts were determined by X-Ray diffraction using a diffractometer PANanalytical $X^{\prime}$ Pert3 Powder and $\mathrm{Cu} \mathrm{K} \alpha$ radiation (PANanalytical, Eindhoven, The Netherlands). The XRD patterns were recorded in a range of $2 \theta=5-90^{\circ}$. The particle sizes were calculated using Scherrer's equation. Reflections at $2 \theta=31.8^{\circ}, 36.2^{\circ}$, and $38.6^{\circ}$ were used for the particle size calculations of the $\mathrm{ZnO}, \mathrm{Cu}$, and $\mathrm{CuO}$ crystallites, respectively. Equilibrium adsorption isotherms of nitrogen were measured at $77 \mathrm{~K}$ using a static volumetric adsorption system (TriFlex analyzer, Micromeritics, Norcross, GA, USA). The samples were degassed at $473 \mathrm{~K}(12 \mathrm{~h})$ prior to an $\mathrm{N}_{2}$ adsorption analysis, in order to obtain a clean surface. The adsorption isotherms were fitted using the Brunauer-Emmett-Teller (BET) method for the specific surface area, the t-plot method for the external specific surface area, and the BJH method for the distribution of mesopores.

The hydrogenolysis of dimethyl adipate ( $>99 \%$, Sigma-Aldrich, s.r.o., Prague, Czech Republic) was carried out in a Parr SS autoclave with a reactor volume of $300 \mathrm{~mL}$ using the prepared CuZn catalysts. Prior to the catalytic tests, all catalysts $(1 \mathrm{~g})$ were reduced in situ in the autoclave at $220^{\circ} \mathrm{C}$ using flowing hydrogen $\left(\mathrm{H}_{2} 99.9 \%\right.$, SIAD Czech, s.r.o., Prague, Czech Republic) at atmospheric pressure for $1 \mathrm{~h}$. After the catalyst reduction, the temperature in the autoclave was decreased to below $100{ }^{\circ} \mathrm{C}$ and the reactor was loaded with $50 \mathrm{~mL}$ of dimethyl adipate (DMA) by a peristaltic pump (i.e., the autoclave with the reduced catalyst was not opened to avoid reoxidation of the catalyst). After that, the temperature in the autoclave was gradually increased to $T=210^{\circ} \mathrm{C}$. Then, the hydrogen pressure was increased to $10 \mathrm{MPa}$ and the catalytic experiment was initiated by starting the stirring of the reaction mixture (DMA with a catalyst) at 600 RPM. Liquid reaction products were periodically withdrawn from the autoclave, centrifuged, and analyzed by a GC (Agilent 6890N, HPST, s.r.o., Prague, Czech Republic) equipped with a FID and non-polar column (ULTRA 1, $0.32 \mathrm{~mm}$ internal diameter, $20 \mathrm{~m}$ length). The DMA conversion was calculated according to Equation (5). Due to the absence of cracking reactions, the $\mathrm{C} 6$ backbone present in the DMA molecule, as well as in the reaction products, was used to calculate the product selectivity (Equation (6)). Methanol (also a reaction product) was excluded from these calculations.

$$
\text { conversion }_{D M A}=\frac{n_{D M A, i}-n_{D M A, t}}{n_{D M A, i}}
$$

where $n_{D M A}$ is the number of DMA moles in the reaction mixture, where $i$ stands for the initial number of DMA moles and $t$ stands for the number of DMA moles at the sampling time. 


$$
S_{x, t}=\frac{n_{x, t}-n_{x, i}}{\sum n_{\text {products } 1 C 6 \text { backbone }}+2 \sum n_{\text {products } 2 C 6 \text { backbones }}+3 \sum n_{\text {products } 3 C 6 \text { backbones }}}
$$

where $S_{x, t}$ is the selectivity to product $x$ at time $t$ of the experiment, $n_{x}$ is the number of moles of product $x$ in the starting/initial mixture (index $i$ ) or at the time of sampling (index $t$ ), $n_{\text {products } y C 6 \text { backbone }}$ refers to the number of product moles having one $(y=1)$, two $(y=2)$ or three $(y=3) C_{6}$ backbones in their molecules.

\section{Conclusions}

The results from the present study show that starting from the same CuZn hydroxycarbonate precursor, it is possible to prepare samples greatly varying in physicochemical properties and catalytic performance. This can be achieved by the thermal treatment of the precursor using different atmospheres (air, nitrogen, and hydrogen) and calcination temperatures $\left(220,350\right.$, and $500{ }^{\circ} \mathrm{C}$ ). Both calcination parameters affected the resulting phase composition of the catalysts as well as their crystallite size. In an oxidizing atmosphere, a mixture of $\mathrm{CuO}$ and $\mathrm{ZnO}$ was produced with increasing crystallite size as the calcination temperature grew. In contrast, in inert or reducing atmospheres, both oxides were accompanied by $\mathrm{Cu}_{2} \mathrm{O}$ and $\mathrm{Cu}$. The crystallite sizes of $\mathrm{Cu}_{2} \mathrm{O}$ and $\mathrm{Cu}$ were larger than the sizes of $\mathrm{CuO}$ and $\mathrm{ZnO}$, thus indicating a less intimate contact between the $\mathrm{Cu}$-phases and $\mathrm{ZnO}$ in catalysts calcined in nitrogen and hydrogen. All three catalysts calcined in different atmospheres at $T=220^{\circ} \mathrm{C}$ demonstrated good activity, resulting in a DMA conversion of $59-63 \%$. The increase in the calcination temperature to $350{ }^{\circ} \mathrm{C}$ resulted in a growth of the DMA conversion to $78 \%$, observed for the sample prepared in the oxidizing atmosphere. This is explained by the small crystallite size and intimate contact between the $\mathrm{CuO}$ and $\mathrm{ZnO}$ phases prior to the catalyst reduction. In contrast, the DMA conversion notably decreased over the samples prepared by the calcination in nitrogen or hydrogen at higher temperatures. This is explained by the decreased number of potentially active sites formed on the interfaces between the $\mathrm{CuO}$ and $\mathrm{ZnO}$ domains after the reduction and the lower stabilization of $\mathrm{Cu}$ crystallites in the $\mathrm{ZnO}$ surrounding. As a result, the DMA conversion decreased to a negligible $1 \%$ observed for samples calcined in $\mathrm{N}_{2}$ and $\mathrm{H}_{2}$ at $500{ }^{\circ} \mathrm{C}$.

Calcination parameters used for the catalyst preparation greatly influenced not only DMA conversion but also product selectivity. The reaction over the air-calcined samples yielded 1,6-hexanediol with selectivity exceeding $20 \%$ at DMA conversion $>10 \%$ independent of the calcination temperature. In contrast, the catalysts calcined in nitrogen or hydrogen at 350 and $500{ }^{\circ} \mathrm{C}$ exhibited selectivity to 1,6 -hexanediol below $2 \%$ at DMA conversion ranging from $1 \%$ to $30 \%$. Transesterification products (demoted $\mathrm{H} 2$ and $\mathrm{H} 3$ ) were the main reaction products with overall selectivities of $>80 \%$ in these cases. The observed change in the catalytic performance of samples prepared by calcination in $\mathrm{N}_{2}$ and $\mathrm{H}_{2}$ allowed for suggesting that different active sites are responsible for the hydrogenolysis and transesterification reaction pathways and that the relative distribution of these sites has changed in dependence on the calcination procedure applied to the starting $\mathrm{CuZn}$ precursor.

Author Contributions: Conceptualization, Methodology and Writing-original draft preparation, O.K. and D.K.; Investigation-experiments and analyses, O.K, J.A., V.P. and M.L.; Writing—review and editing, J.A., V.P. and D.K.

Funding: This research was funded by the Czech Science Foundation (project No. GA17-05704S).

Acknowledgments: This work was realized within the Operational Programme Prague-Competitiveness (CZ.2.16/3.1.00/24501) and "National Program of Sustainability" (NPU I LO1613) MSMT-43760/2015.

Conflicts of Interest: The authors declare no conflict of interest. 


\section{Appendix A}

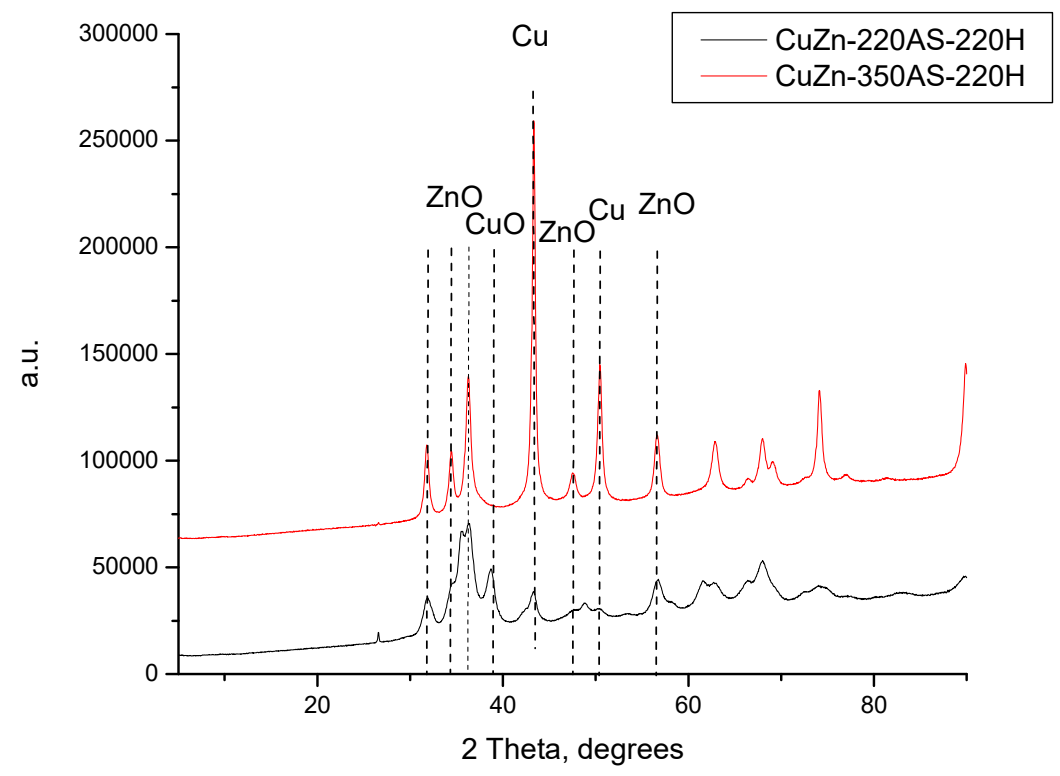

Figure A1. The XRD patterns of catalyst samples prepared by the treatment of the CuZn precursor in static air at 220 and $350{ }^{\circ} \mathrm{C}$ followed by the treatment in a hydrogen at $\mathrm{T}=220^{\circ} \mathrm{C}$.

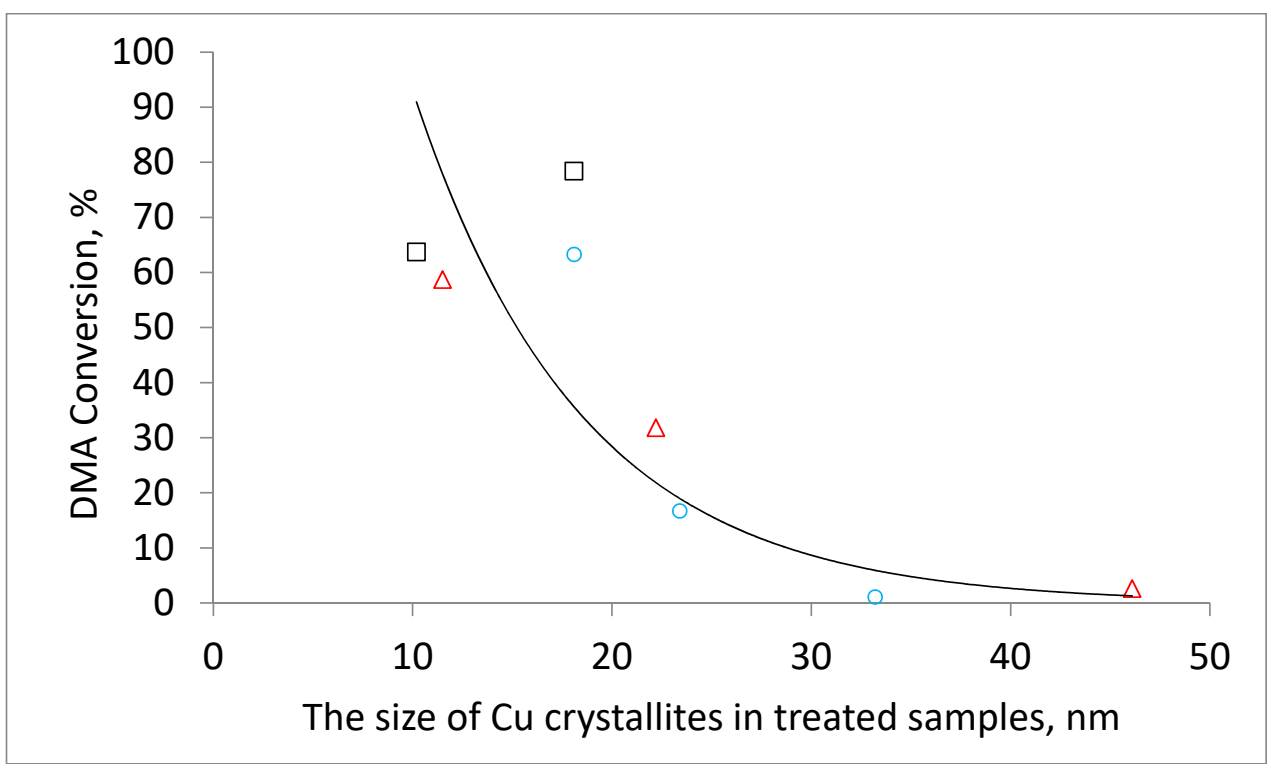

Figure A2. A correlation between the DMA conversion and the size of the $\mathrm{Cu}$ crystallites in the prepared CuZn catalysts. $\square$ : calcined in air, $\Delta$ : calcined in nitrogen, $\bigcirc$ : calcined in hydrogen.

\section{References}

1. Adkins, H.; Folkers, K. The catalytic hydrogenation of esters to alcohols. J. Am. Chem. Soc. 1931, 53, 1095-1097. [CrossRef]

2. Turek, T.; Trimm, D.L. The catalytic hydrogenolysis of esters to alcohols. Catal. Rev.-Sci. Eng. 1994, 36, 645-683. [CrossRef]

3. Adkins, H. Catalytic hydrogenation of esters to alcohols. Org. React. 1954, 8, 1-27.

4. Zhu, Y.-M.; Shi, L. Zn promoted Cu-Al catalyst for hydrogenation of ethyl acetate to alcohol. J. Ind. Eng. Chem. 2014, 20, 2341-2347. [CrossRef] 
5. Yuan, P.; Liu, Z.; Hu, T.; Sun, H.; Liu, S. Highly efficient Cu-Zn-Al catalyst for the hydrogenation of dimethyl adipate to 1,6-hexanediol: Influence of calcination temperature. React. Kinet. Mech. Catal. 2010, 100, 427-439. [CrossRef]

6. Kubička, D.; Aubrecht, J.; Pospelova, V.; Tomášek, J.; Šimáček, P.; Kikhtyanin, O. On the importance of transesterification by-products during hydrogenolysis of dimethyl adipate to hexanediol. Catal. Commun. 2018, 111, 16-20. [CrossRef]

7. Zander, S.; Kunkes, E.L.; Schuster, M.E.; Schumann, J.; Weinberg, G.; Teschner, D.; Jacobsen, N.; Schloegl, R.; Behrens, M. The Role of the Oxide Component in the Development of Copper Composite Catalysts for Methanol Synthesis. Angew. Chem. Int. Ed. 2013, 52, 6536-6540. [CrossRef] [PubMed]

8. Behrens, M.; Studt, F.; Kasatkin, I.; Kuehl, S.; Haevecker, M.; Abild-Pedersen, F.; Zander, S.; Girgsdies, F.; Kurr, P.; Kniep, B.-L.; et al. The Active Site of Methanol Synthesis over $\mathrm{Cu} / \mathrm{ZnO} / \mathrm{Al}_{2} \mathrm{O}_{3}$ Industrial Catalysts. Science 2012, 336, 893-897. [CrossRef] [PubMed]

9. Behrens, M.; Kissner, S.; Girsgdies, F.; Kasatkin, I.; Hermerschmidt, F.; Mette, K.; Ruland, H.; Muhler, M.; Schloegl, R. Knowledge-based development of a nitrate-free synthesis route for $\mathrm{Cu} / \mathrm{ZnO}$ methanol synthesis catalysts via formate precursors. Chem. Commun. 2011, 47, 1701-1703. [CrossRef] [PubMed]

10. Fujita, S.-I.; Moribe, S.; Kanamori, Y.; Kakudate, M.; Takezawa, N. Preparation of a coprecipitated Cu/ZnO catalyst for the methanol synthesis from $\mathrm{CO}_{2}$-Effects of the calcination and reduction conditions on the catalytic performance. Appl. Catal. A 2001, 207, 121-128. [CrossRef]

11. Natesakhawat, S.; Lekse, J.W.; Baltrus, J.P.; Ohodnicki, P.R.; Howard, B.H.; Deng, X.; Matranga, C. Active Sites and Structure-activity Relationships of Copper based Catalysts for Carbon Dioxide Hydrogenation to Methanol. ACS Catal. 2012, 2, 1667-1676. [CrossRef]

12. Wang, S.; Liu, H. Selective hydrogenolysis of glycerol to propylene glycol on Cu-ZnO catalysts. Catal. Lett. 2007, 117, 62-67. [CrossRef]

13. Hu, Q.; Fan, G.; Yang, L.; Li, F. Aluminum-doped zirconia-supported copper nanocatalysts: Surface synergistic catalytic effects in the gas-phase hydrogenation of esters. Chemcatchem 2014, 6, 3501-3510. [CrossRef]

14. Schumann, J.; Tarasov, A.; Thomas, N.; Schlögl, R.; Behrens, M. Cu,Zn-based catalysts for methanol synthesis: On the effect of calcination conditions and the part of residual carbonates. Appl. Catal. A 2016, 516, 117-126. [CrossRef]

15. Millar, G.J.; Holm, I.H.; Uwins, P.J.R.; Drennan, J. Characterization of precursors to methanol synthesis catalysts $\mathrm{Cu} / \mathrm{ZnO}$ system. J. Chem. Soc. Faraday Trans. 1998, 94, 593-600. [CrossRef]

16. Seciuin, M.K. Thermogravimetric and differential thermal analysis of malachite and azurite in inert atmospheres and in air. Can. Mineral. 1975, 13, 127-132.

17. Qi, G.-X.; Zheng, X.-M.; Fei, J.-H.; Hou, Z.-Y. A novel catalyst for DME synthesis from CO hydrogenation 1. Activity, structure and surface properties. J. Mol. Catal. A Chem. 2001, 176, 195-203. [CrossRef]

18. King, H.P.; Alexander, L.E. X-ray Diffraction Procedures, 2nd ed.; Wiley: New York, NY, USA, 1973.

19. Santos, S.M.; Silva, A.M.; Jordão, E.; Fraga, M.A. Hydrogenation of dimethyl adipate over bimetallic catalysts. Catal. Commun. 2004, 5, 377-381. [CrossRef]

(C) 2018 by the authors. Licensee MDPI, Basel, Switzerland. This article is an open access article distributed under the terms and conditions of the Creative Commons Attribution (CC BY) license (http://creativecommons.org/licenses/by/4.0/). 